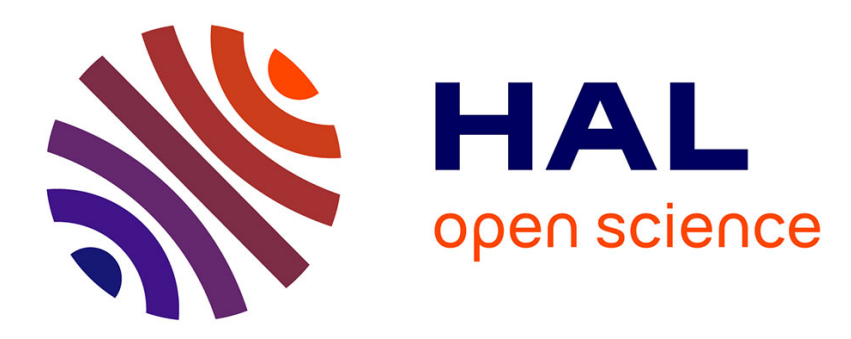

\title{
AN EFFECT OF SPECIMEN SIZE IN THE HIGH STRAIN RATE COMPRESSION TEST
}

\author{
D. Gorham
}

\section{To cite this version:}

D. Gorham. AN EFFECT OF SPECIMEN SIZE IN THE HIGH STRAIN RATE COMPRESSION TEST. Journal de Physique IV Proceedings, 1991, 01 (C3), pp.C3-411-C3-418. 10.1051/jp4:1991358 . jpa-00250502

\section{HAL Id: jpa-00250502 https://hal.science/jpa-00250502}

Submitted on 1 Jan 1991

HAL is a multi-disciplinary open access archive for the deposit and dissemination of scientific research documents, whether they are published or not. The documents may come from teaching and research institutions in France or abroad, or from public or private research centers.
L'archive ouverte pluridisciplinaire HAL, est destinée au dépôt et à la diffusion de documents scientifiques de niveau recherche, publiés ou non, émanant des établissements d'enseignement et de recherche français ou étrangers, des laboratoires publics ou privés. 


\title{
AN EFFECT OF SPECIMEN SIZE IN THE HIGH STRAIN RATE COMPRESSION TEST
}

\author{
D. A. GORHAM \\ The Open University, Faculty of Technology, Walton Hall, \\ Milton Keynes,GB-MK7 6AA, Great-Britain
}

\begin{abstract}
Résumé: On sait que la contrainte d'écoulement de plusieurs métaux varie avec la vitesse de déformation de façon plus importante au-delà d'une certaine vitesse critique $\dot{\varepsilon}_{\mathrm{c}}$. Dans cet exposé une analyse des mesures antérieures sur le cuivre indique que la valeur de $\dot{\varepsilon}_{\mathrm{c}}$ dépend fortement de la dimension des éprouvettes et pourrait ne pas être entièrement représentative des propriétés propres au matériau. L'estimation de la contrainte d'inertie montre que dans une telle observation l'inertie pourrait jouer un rôle important. Des arguments quantitatifs suggèrent que la vitesse de déformation, la friction et la propagation d'ondes pourraient aussi contribuer à cet effet.
\end{abstract}

\begin{abstract}
The flow stress of many metals is known to vary more strongly with strain rate above a critical value $\dot{\varepsilon}_{c}$ than below it. In this paper an analysis of previous authors' measurements on copper indicates that the value of $\dot{\varepsilon}_{c}$ is highly dependent upon specimen size and so it may not be fully representative of inherent material properties. An estimate of inertial stress shows that inertia may be an important mechanism behind this observation. Qualitative arguments suggest that deformation velocity, friction and wave propagation could also contribute.
\end{abstract}

\section{INTRODUCTION}

It has been observed by many previous workers that some metals display the high strain rate behaviour sketched in figure 1 . Up to a critical value of strain rate, $\dot{\varepsilon}_{c}$, the flow stress corresponding to a certain strain value increases linearly with the logarithm of strain rate. This is generally acknowledged to be a consequence of the role of thermal activation in the control of deformation mechanics. Above $\dot{\varepsilon}_{c}$ the flow stress increases more rapidly with strain rate, with an approximately linear relationship. In the past, this behaviour was generally interpreted to be an indication that velocity-dependent "drag" on dislocation motion is causing an additional limitation to deformation. However, recent work by several authors (for example Follansbee \& Kocks /1/ and Klepaczko /2/) has shown in the case of copper and some other f.c.c. metals that a transition to drag-controlled deformation is not a likely explanation, and that the observed behaviour can be more accurately interpreted as a change in the way that structure evolves with strain. Microstructural observation supports this view by showing that the occurrence of twinning is much more common in specimens deformed at a rate above $\dot{\varepsilon}_{c}$ (Chiem /3/ and Haque et al /4/). 


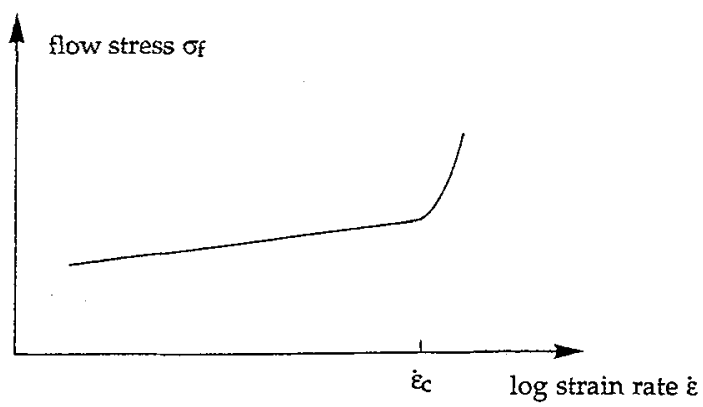

Figure 1: The stress/strain-rate relationship that is typical of many metals

\section{SPECIMEN SIZE DEPENDENCE IN COPPER}

Copper is the most widely studied metal at high strain rates and many authors have found behaviour like Figure 1 with this material, most commonly in compression but also in tension and torsion. However, a large variation in the value of $\dot{\varepsilon}_{\mathrm{c}}$ has been found, ranging in compression tests over two orders of magnitude from $\sim 4 \times 10^{2}$ (Kumar \& Kumble /5/) to $\sim 2.5 \times 10^{4}$ (Gorham, Pope \& Field /6/), and a number of examples are listed in Table 1 .

Table 1: Summary of dynamic compression tests on copper

\begin{tabular}{|l|l|l|l|l|l|}
\hline & $\begin{array}{l}\text { axial strain } \\
\text { rate at } \\
\text { transition } \\
\dot{\varepsilon}_{\mathrm{c}} / \mathrm{s}^{-1}\end{array}$ & $\begin{array}{l}\text { specimen } \\
\text { diameter } \\
\mathrm{d} / \mathrm{mm}\end{array}$ & $\begin{array}{l}\text { specimen } \\
\text { length } \\
\mathrm{h} / \mathrm{mm}\end{array}$ & $\begin{array}{l}\text { axial } \\
\text { velocity } \\
\mathrm{u}_{\mathrm{c}} / \mathrm{ms}^{-1}\end{array}$ & $\begin{array}{l}\text { radial } \\
\text { velocity } \\
\mathrm{v}_{\mathrm{rc}} / \mathrm{ms}^{-1}\end{array}$ \\
\hline Gorham et al $/ 6 /$ & $2.5 \times 10^{4}$ & 1.0 & 0.6 & 15.0 & 6.3 \\
\hline Shioiri et al $/ 7 /$ & $1.3 \times 10^{4}$ & 2.0 & 2.0 & 26.0 & 6.5 \\
\hline Follansbee et al /8/ & $1 \times 10^{4}$ & 3.8 & 2.3 & 23.0 & 9.5 \\
\hline Parry \& Walker /9/ & $2 \times 10^{3}$ & 10.0 & 4.3 & 8.6 & 5.0 \\
\hline Edington /10/ & $1.2 \times 10^{3}$ & 12.5 & 2.0 & 2.4 & 3.8 \\
\hline Stelly \& Dormeval $/ 11 /$ & $1 \times 10^{3}$ & 5.0 & 5.0 & 5.0 & 1.3 \\
\hline Buchar et al $/ 12 /$ & $0.9 \times 10^{3}$ & 14.0 & 2.0 & 1.8 & 3.2 \\
\hline Kumar \& Kumble $/ 5 /$ & $4 \times 10^{2}$ & 10.0 & 12.7 & 5.1 & 1.0 \\
\hline
\end{tabular}

All these results are from tests which were geometrically similar, namely the dynamic, axial compression of short cylindrical specimens, carried out using the split Hopkinson pressure bar or variations of this technique. (Some of these authors have presented results in terms of an equivalent shear strain: these have been converted back to axial strain in Table 1.) It should be noted that there is a considerable variation in specimen size in the studies, and Table 1 also lists values for the specimen diameter and length that characterise each case. What is particularly significant about the large variation in $\dot{\varepsilon}_{\mathrm{c}}$ is that it appears to be related to specimen dimensions: in general, the larger specimens are associated with low values for $\dot{\varepsilon}_{c}$ and the smaller specimens with much higher values.

Figure 2 illustrates this trend more clearly, by plotting these measured values of $\dot{\varepsilon}_{\mathcal{C}}$ against specimen diameter $d$, both on logarithmic scales. The line drawn through these points is a least-squares fit, equivalent to a relationship of $\dot{\varepsilon}_{\mathrm{C}} \propto \mathrm{d}^{-1.4}$. In view of the wide variation in materials and experimental conditions between these results from different authors, the link between $\dot{\varepsilon}_{c}$ and d does seem to be remarkably consistent. Specimen height is a less satisfactory parameter as a characteristic dimension since many authors vary it to achieve variation of strain rate, but a similar but rather more scattered relationship is found by plotting $\dot{\varepsilon}_{\mathrm{c}}$ against specimen height $h$. A much closer fit is found between $\dot{\varepsilon}_{\mathrm{c}}$ and the product $h \times d$, of the form $\dot{\varepsilon}_{\mathrm{c}} \propto(\mathrm{hd})^{-0.84}$. 
These observations, although purely empirical, do cast some doubt over the interpretation of $\dot{\varepsilon}_{\mathrm{c}}$. If it is not purely a result of inherent material properties, then the observed behaviour of the transition at $\dot{\varepsilon}_{c}$ may be influenced by one or more mechanisms from the following three groups. First are imperfections in the technique, such as lubrication breakdown leading to high interfacial friction. Second are physical processes inherent in homogeneous deformation, such as effects of deformation velocity and inertia. Third is the development of inhomogeneous deformation due to wave propagation. In each case the observed increase in stress at a given strain can be due to the mechanism itself, or to an interaction between the mechanism and rate dependent material properties. The rest of the paper will consider contributions from these main areas.

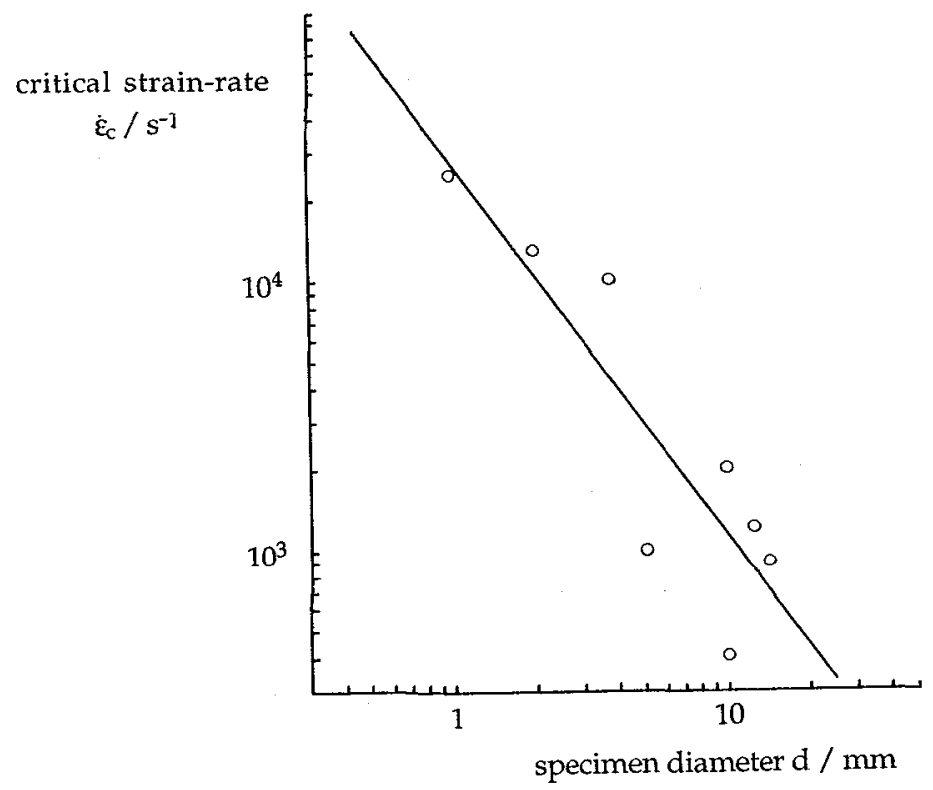

Figure 2: Values of the critical strain rate from Table 1, plotted against specimen diameter.

\section{DEFORMATION VELOCITY}

In the ideal compression test where deformation is uniform under a compression velocity $u$, the strain rate at any point in the specimen is given by

$$
\dot{\varepsilon}=\mathrm{u} / \mathrm{h}
$$

where $\mathrm{h}$ is the current height of the specimen. This introduces a direct effect of size: to reach a given value of strain rate, a longer specimen needs to be subjected to a proportionately higher compression velocity than a shorter one. Deformation is controlled by wave propagation and by dislocation motion within the specimen, processes which are associated with absolute velocities and characteristic times. Also material inertia and interfacial friction conditions are both velocity dependent phenomena which can affect deformation stresses. Hence it is likely that two situations with the same macroscopic strain rate but with differing size and hence differing impact velocities will display variations in deformation behaviour.

Most authors have covered at least part of their range of strain rate values by altering compression velocity with constant specimen dimensions, and so many observations of $\dot{\varepsilon}_{\mathcal{C}}$ are in fact directly related to changes in this velocity. 
The average deformation velocities calculated from equation 1 and corresponding to the value of $\dot{\varepsilon}_{\mathrm{c}}$ for each test are listed in column 5 of Table 1 . Although rather scattered, the values correspond roughly to a relationship of the form $u_{c} \propto d^{-1}$. Hence there is no indication of a constant threshold value of $u_{c}$ being the controlling factor in the observations of $\dot{\varepsilon}_{\mathrm{c}}$.

The radial velocity experienced by points on the circumference of the specimen is given by

$$
v_{r}=u d / 4 h=\frac{\dot{\varepsilon} d}{4}
$$

Values for $v_{r c}$ corresponding to each $\dot{\varepsilon}_{\mathrm{c}}$ are also given in the table, showing a similar pattern to the values of $u_{c}$ but with a much less well defined correlation with diameter or length. Thus there is no evidence of a constant value of either axial or radial velocity linked to the observed behaviour of $\dot{\varepsilon}_{\mathrm{c}}$.

\section{4. $\quad$ FRICTION}

Interfacial friction is a potential source of error in all forms of the axial compression test. Many authors have tried to establish the influence of frictional restraint by using specimens over a range of $\mathrm{h} / \mathrm{d}$ ratios, including Lindholm /13/, Holzer \& Brown /14/ and Malinowski \& Klepaczko /15/. A quantitative measurement of frictional parameters by Gorham, Pope \& Cox /16/ indicates that friction conditions in the dynamic compression test are very variable, and that great care is needed to avoid lubricant breakdown.

Specimen size can be an important influence on friction, since larger specimens deformed at the same strain rate involve longer radial displacements at higher velocities than in the case of small specimens. Lubricant breakdown is more likely under large displacements (Pearsall \& Backofen /17/) and loss of lubricant by jetting is enhanced at high velocities (Gorham /18/). Hence these large specimens may be subject to a velocity dependent frictional restraint, contributing to the observed behaviour at $\dot{\varepsilon}_{\mathrm{c}}$. Geometric variations of measured flow stress found by Holzer \& Brown /14/ have been ascribed to such a mechanism.

It may be significant that the two configurations in Table 1 in which the $\dot{\varepsilon}_{c}$ transition was observed at the lowest impact velocities, references $/ 10 /$ and $/ 12 /$, were those in which the specimen $h / d$ ratios were also very low. According to Siebel /19/ the average pressure needed to deform a material of yield strength $\sigma_{\mathrm{y}}$ is

$$
\overline{\mathrm{P}}=(1+2 \mu \mathrm{a} / 3 \mathrm{~h}) \sigma_{\mathrm{y}}
$$

where $\mu$ is the coefficient of friction, a the specimen radius and $h$ its height. With well prepared surfaces and an appropriate lubricant, the minimum value of $\mu$ is expected to be about 0.02 (Davies \& Hunter /20/and Gorham et al / 16/). For the aspect ratios used in references $/ 10 /$ and $/ 12 /$, this value of $\mu$ suggests a minimum error in $\sigma_{y}$ of about $4 \%$ even when the lubrication is fully effective. A limited amount of breakdown due to increasing radial interfacial velocity would increase the average value of $\mu$ enough for the measured differences in $\sigma_{\mathrm{y}}$ to appear as a significant strain rate effect. Thus the size and velocity dependent changes in lubrication conditions may have contributed to the observed behaviour of $\dot{\varepsilon}_{c}$ in at least these two cases.

\section{INERTIA}

The possibility of the inertia of the deforming specimen influencing measured stress has been recognised since the experiments of Kolsky /21/, who used an energy balance 
argument to predict inertial stresses developed during uniform deformation of a discshaped specimen. This analysis has subsequently been extended to cover more realistically a wider range of experimental situations by Davies \& Hunter /20/, Haddow /22/, Samanta $/ 23 /$ and Gorham /24/. For a specimen of height $h$ and radius a deforming uniformly at a strain rate $\dot{\varepsilon}$ on a rigid anvil, the inertial component of stress measured at the anvil is given by

$$
\sigma_{i}=\rho\left(\frac{a^{2}}{16}+\frac{h^{2}}{6}\right) \dot{\varepsilon}^{2}+\rho\left(\frac{h^{2}}{6}-\frac{a^{2}}{8}\right) \ddot{\varepsilon}
$$

Numerical simulation $(/ 24 /)$ of uniform deformation has shown that in many cases the $\dot{\varepsilon}^{2}$ and $\ddot{\varepsilon}$ terms are of the same order of magnitude. Thus in a given experimental situation, the total inertial stress rises rapidly with $\dot{\varepsilon}$ and with specimen dimensions. The effect will become particularly noticeable in test results when the inertial stress reaches, say, 10\% of the measured flow stress $\sigma_{f}$. In the case of copper, $\sigma_{\mathrm{f}} \approx 250 \mathrm{MPa}$ at plastic strains of around $10 \%$, and so $\sigma_{\mathrm{i}} \approx 25 \mathrm{MPa}$ can be taken to represent an approximate threshold for inertial effects to be significant. Adding the common condition in experimental work that $a \approx h$ yields the following relationship for the threshold value $\dot{\varepsilon}_{t}$ at which the $\dot{\varepsilon}^{2}$ term is equal to 12.5 $\mathrm{MPa}$, half the above stress value:

$$
\mathrm{d} \dot{\varepsilon}_{\mathrm{t}} \approx 1.6 \times 10^{2} \mathrm{~ms}^{-1}
$$

This relationship is plotted as line A in Figure 3, where it can be seen to lie significantly above the experimental results. This indicates that inertia arising from the assumption of steady and uniform deformation is not likely to be significant.

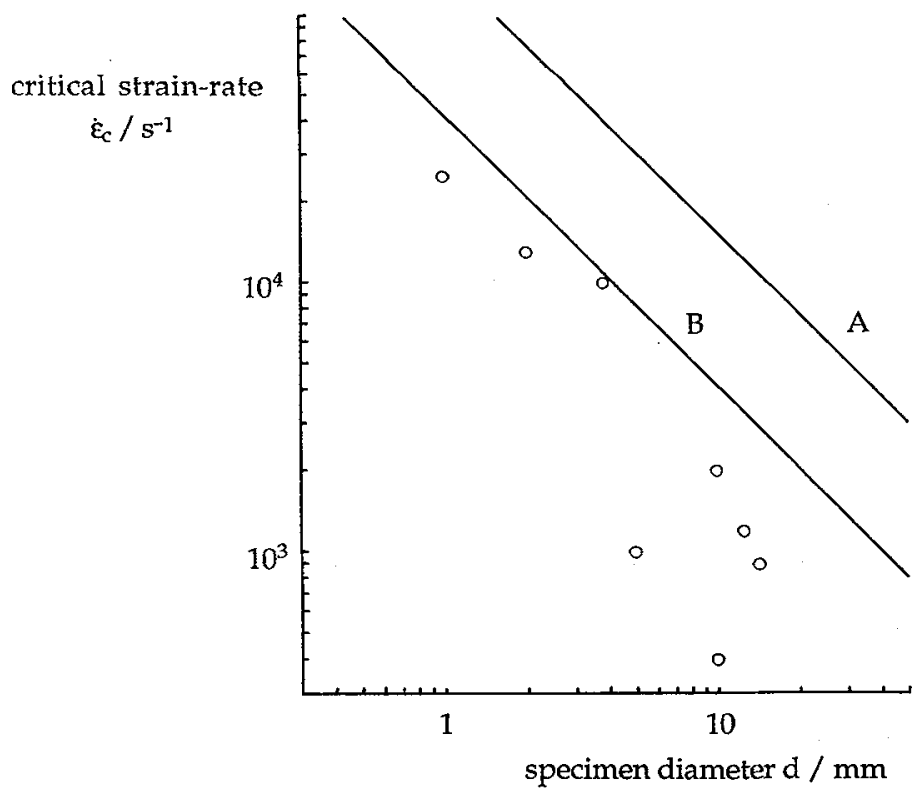

Figure 3: Inertia criteria of equations 5 (line A) and 7 (line B), with results of Table 1

However, in the early stages of deformation the term in $\ddot{\varepsilon}$, the rate of change of strain rate, can be very high, and an estimate of transient inertial effects arising during this phase can be made as follows. Due to dispersion, the loading pulse propagating in a Hopkinson bar arrangement typically has a risetime in microseconds numerically approximating to the bar diameter (D) in millimetres. Therefore, if the specimen strain rate $\dot{\varepsilon}$ is to be fully established during this rise time, the average value of $\ddot{\varepsilon}$ over the interval is 


$$
\ddot{\varepsilon} \approx \frac{\dot{\varepsilon} \times 1000}{\mathrm{D}} \approx \frac{\dot{\varepsilon} \times 800}{\mathrm{~d}}
$$

where it is assumed that specimen diameter $d=0.8 \mathrm{D}$. (A similar estimate of $\ddot{\varepsilon}$ can be made by considering longitudinal plastic wave propagation in the specimen.) Using this empirical link the relationship defined by setting the term $\rho h^{2} \ddot{\varepsilon} / 6=12.5 \mathrm{MPa}$ becomes

$$
\mathrm{d} \dot{\varepsilon}_{\mathrm{t}} \approx 42 \mathrm{~ms}^{-1}
$$

This is plotted as line B in Figure 3, and lies very close to the experimental data. From a two-dimensional numerical analysis of the split Hopkinson pressure bar, Bertholf \& Karnes /25/ derive the inertia-controlled limit of reliable operations as $D \dot{\varepsilon}_{\max }=50 \mathrm{~ms}^{-1}$, equivalent to $\mathrm{d} \dot{\varepsilon}_{\max }=40 \mathrm{~ms}^{-1}$ if $\mathrm{d}=0.8 \mathrm{D}$, as above. This agrees very closely with the empirically based criterion in equation 7. (However, the Bertholf \& Karnes criterion is based on a ramped input loading with a rise time of $1.6 \mu$ s per millimetre of bar diameter, and would be slightly more severe with the dispersion-limited rate of $1 \mu$ s per millimetre used to calculate equation 7.) Thus there are strong grounds for supposing that some measurements of $\dot{\varepsilon}_{c}$ may be influenced by the development of inertial stresses.

Although the contribution to measured stress predicted by the above analysis is transient, it is likely that this overshoot in stress seriously affects the nucleation and early growth of defects and so influences the whole of the deformation cycle. This point is discussed further in the next two sections.

\section{INHOMOGENEOUS DEFORMATION}

In a purely uniform compression, then direct effects upon the deformation mechanics would only occur when the compression velocity was an appreciable fraction of plastic wave and other limiting velocities. However, in practice the compression is not uniform, particularly at the start of deformation, and this introduces further mechanisms that are dependent upon specimen dimensions.

For example, the two specimens in Figure 4(a) and (b) are of the same aspect ratio but differ in dimensions by a factor of 3 . At the same strain rate the imposed compression velocities are also in this ratio. Assuming that the deformation is uniform, then the upper and lower surfaces of the section marked $X$ in the larger specimen have velocities of $3 u$ and $2 u$ respectively, their difference being the same deformation velocity, $u$, as that of the smaller specimen. However, section $X$ has the additional rigid body component of $2 u$. Thus the two sections are not in identical dynamic situations, and particularly while deformation fields are being established by elastic and plastic wave propagation, the local strain histories of the two cases can be very different. The initial loading rate of the larger specimen is much greater because of the higher surface velocity, and wave reflections from the anvil arrive back later than in the small specimen. Also section $X$ has the constraint of surrounding material, which provides an additional radial stress component for the time it takes a release wave to propagate in from the free surface $/ 26 /$. The related effects of inertia also causes variations of stress according to the local deformation fields in each case.

Thus, to reach a given strain rate the stress history in a smaller specimen generally reaches equilibrium much sooner than a larger one, and involves smaller fluctuations around the mean value. It is now well established that dislocation structures, and hence the future behaviour of the material, are dependent upon the rate of application and duration of loading. In particular, the nucleation of dislocations and the formation of loops and twins is very sensitive to the magnitude and timescale of the imposed stress (eg Chiem / $/ 3 /$ and Gray \& Follansbee $/ 27 /$ ). Hence the strain history at each point in the specimen, composed 


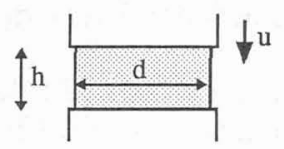

(a)

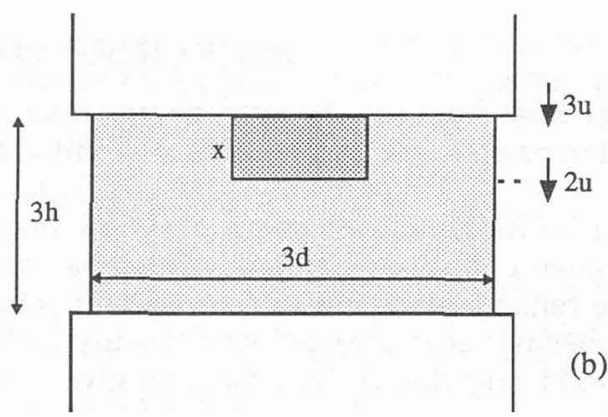

Figure 4: Axial compression against a rigid anvil for two specimen sizes.

of many transient loadings and unloadings which vary with dimensions, controls the fermation and growth of these defects and so leads to an overall mechanical behaviour which is likely to be dependent on specimen size. However, because of the limited accuracy with which wave propagation effects can be modelled, and the poorly understood nature of dislocation mechanics under high rate deformation, a quantitative estimate of these effects and a link to the observed behaviour of $\dot{\varepsilon}_{\mathcal{C}}$ and $u_{c}$ cannot be made in the context of this paper.

\section{DISCUSSION}

The strongest evidence at present for a size-dependent contribution to observed values of $\dot{\varepsilon}_{c}$ comes from basic considerations of inertia. The above analysis has shown that measurements of $\dot{\varepsilon}_{\mathrm{c}}$ are in general on the border of where inertial stresses are significant. Although largest effects are likely to be occurring only while the bulk deformation rate is being established, the resulting changes to the development of microstructure could be affecting all subsequent deformation.

The simple empirical criterion of equation 7 agrees very closely with results of the numerical simulation of Bertholf \& Karnes $/ 25 /$, and both follow, in form and magnitude, the average variation of $\dot{\varepsilon}_{c}$ with specimen diameter found by previous workers. Experimental evidence that inertia is significant comes from the common observation that stress values at each end of the specimen, calculated from waves propagating in each bar, begin to differ at higher strain rates (for example, reference $/ 28 /$ ).

Many authors have assumed that inertia is negligible by employing specimens of an aspect ratio $h / d=\sqrt{3} / 2$, which reduces the $\ddot{\varepsilon}$ term in equation 4 to zero. There are, however, three problems with this approach.

1) The criterion is based upon the early analysis of Davies \& Hunter $/ 20 /$, which resulted in only the $\ddot{\varepsilon}$ term of equation 4 . More complete analyses add the $\dot{\varepsilon}^{2}$ term $(/ 22 /$ and $/ 23 /$ )and an overall translation term $(/ 24 /)$ which do not provide the opportunity for cancellation.

2) The cancellation within the $\ddot{\varepsilon}$ term only applies to stress measured in the output bar of the split Hopkinson bar apparatus. Most authors using the Davies-Hunter criterion have calculated stress results from the average stress between the two specimen faces for which a different equation (/24/) applies that does not produce cancellation.

3) Even if there is perfect cancellation in the measured stress value, the individual components of axial and radial inertia are still present in the material, and are likely to be affecting the homogeneity of deformation and of the development of microstructure.

Thus it is not possible to eliminate the effects of inertia by selecting an appropriate geometry. Errors can be reduced by controlling the loading rate to minimise the $\ddot{\varepsilon}$ contribution, although a careful analysis is necessary for each experimental situation to estimate the remaining inertial contribution. 
There is also some evidence that the effects of frictional restraint arising from lubricant breakdown can be significant, especially for specimens of a very flat aspect ratio. However, in any experimental situation the average frictional force can be quantified by the ring test $/ 16 /$ and so the presence of a significant restraint should be independently detectable.

The degree of influence that wave propagation, inertia and the effects of inhomogeneous deformation have upon time dependent material characteristics is very difficult to assess without more reliable models of dislocation micromechanics. However, it seems likely that material behaviour is changed significantly by the detailed differences in strain history and strain rate history that distinguish, at a given average macroscopic strain rate, one experiment from another with a different geometry. Hence the interpretation of $\dot{\varepsilon}_{\mathrm{c}}$ must be treated with some caution until more accurate modelling can be achieved.

\section{8. $\quad$ REFERENCES}

/1/ Follansbee PS \& Kocks UF 1988, Acta Metall 36 (1) 81-93

/2/ Klepaczko JR 1988 in Impact loading and dynamic behaviour of materials ed Chiem

CY, Kunze H-D \& Meyer LW (DGM Informationsgesellschaft Verlag) pp 823-830

13/ Chiem CY, 1988 in Impact loading and dynamic behaviour of materials ed Chiem CY, Kunze H-D \& Meyer LW (DGM Informationsgesellschaft Verlag) 57-76

/4/ Haque MM, Pickering FB \& Hashmi MSJ 1988 J de Physique 49 Supp No 9 C3 103-108

/5/ Kumar A \& Kumble RG, 1969 J Appl Phys 40 (9) 3475-3480

/6/ Gorham DA, Pope PH \& Field JE 1991 (submitted for publication)

/7/ Shiori J, Satoh K \& Nishimura K 1978 in High velocity deformation of solids ed

Kawata K \& Shioiri J (Berlin: Springer-Verlag) pp 51-66

18/ Follansbee PS, Regazzoni G \& Kocks UF 1984 in Mechanical properties at high rates of strain 1984 ed J Harding (Bristol: The Institute of Physics) 71-80

19/ Parry DJ \& Walker AG 1989 in Mechanical properties at high rates of strain 1989 ed J Harding (Bristol: The Institute of Physics) pp 329-336

/10/ Edington JW 1969 Phil Mag, 19 1189-1206

/11 Stelly M \& Dormeval R 1978 in High velocity deformation of solids ed Kawata K \& Shioiri J (Berlin: Springer-Verlag) pp 82-97

/12/ Buchar J, Bilek Z \& Dusek F 1986 Mechanical behaviour of metals at extremely high rates of strain (Switzerland: Trans Tech Publications) p108

/13/ Lindholm U 1964 J Mech Phys Solids 12 317-335

/14/ Holzer AJ \& Brown RH 1979 Trans ASME: J Eng Mat and Tech 101, 238-247

/15/ Malinowski JZ \& Klepaczko JR 1986 Int J Mech Sci 28, 6, 381-391

/16/ Gorham DA, Pope PH \& Cox O 1984 in Mechanical properties at high rates of strain 1984 ed J Harding (Bristol: The Institute of Physics) 151-158

/17/ Pearsall GW \& Backofen WA 1963 Trans ASME: J Eng Ind 85 68-76

/18/ Gorham DA 1979 in Mechanical properties at high rates of strain 1979 ed J Harding (Bristol: The Institute of Physics) 16-24

/19/ Siebel E 1923 Stahl und Eisen 4331295

/20/ Davies EDH \& Hunter SC 1963 J Mech Phys Solids 11 155-179

/21/ Kolsky H 1949 Proc Phys Soc B62, 676-700

/22/ Haddow JB 1965 Int J Mech Sci $7657-660$

/23/ Samanta SK 1971 J Mech Phys Solids $\underline{19}$ 117-135

/24/ Gorham DA 1989 J Phys D: Appl Phys 22 1888-1893

/25/ Bertholf LD \& Karnes CH 1975 J Mech Phys Solids 23, 1-19

/26/ Tanaka K, Kurokawa T \& Ueda K 1987 in Macro- and micro-mechanics of high velocity deformation and fracture ed Kawata K \& Shiori J (Berlin: Springer-Verlag) 317-326 /27/ Gray GT \& Follansbee PS 1988 in Impact loading and dynamic behaviour of materials ed Chiem CY, Kunze H-D \& Meyer LW (DGM Informationsgesellschaft Verlag) pp 541-548 /28/ Follansbee PS in Metallurgical applications of shock-wave and high-strain-rate phenomena, ed Murr LE, Staudhammer KP \& Meyers MA (New York:Dekker) 451-479 